\title{
DST NO ÂMBITO DA RELAÇÃO ESTÁVEL: ANÁLISE CULTURAL COM BASE NA PERSPECTIVA DA MULHER
}

\section{STD in scope of long-term relationships: cultural analysis based on women's perspective \\ EST en el ámbito de la relación estable: análisis cultural con base en la perspectiva de la mujer}

Maria Grasiela Teixeira Barroso²

\section{RESUMO}

0 trabalho teve como objetivo analisar as significações da contaminação por DST para a mulher em união estável. Trata-se de uma pesquisa etnográfica, baseada na Teoria do Cuidado Cultural. Desenvolveu-se o estudo no Centro de Desenvolvimento Familiar (CEDEFAM) e no contexto familiar de sete mulheres, durante nove meses. Os resultados mostraram que o diagnóstico de DST influencia o comportamento sexual das mulheres. Em face disso, todavia, verificou-se que os homens parecem se comportar como coadjuvantes no processo e ainda consideram o problema como inerente apenas à parte feminina. Conclui-se que é imprescindível a abordagem da cultura nas ações de Educação em Saúde para a promoção da saúde sexual e reprodutiva do casal.

Palavras-chave: Doenças Sexualmente Transmissíveis. Saúde da Mulher. Enfermagem.

\begin{abstract}
This study aimed to analyze the meaning of STD contamination for the women with stable union. The present study is an ethnographical research, based on Theory of Cultural Care. The study was developed in the Center of Family Development (CEDEFAM) and in seven women's family context for nine months. The results showed that the STD diagnosis influences on women's sexual behavior. On the other hand, it was verified that men seem to behave as having a secondary role in the process and still consider the problem a feminine one. As a conclusion, it was noticed the importance of the approach of culture in Health Education actions for the promotion of couple's sexual and reproductive health.
\end{abstract}

Keywords: Sexually Transmitted Diseases. Womens's Health. Nursing.

\section{Resumen}

El estudio tuvo la intención de analizar las significaciones de contaminación por EST para la mujer en unión estable. Se trata de una pesquisa etnográfica, basada en la Teoría Cultural. El estudio ocurrió en el Centro de Desarrollo Familiar (CEDEFAM) y en el contexto familiar de siete mujeres durante nueve meses. Los resultados mostraran que el diagnóstico de EST influencia el comportamiento sexual de las mujeres. Todavía, se verificó que los hombres parecen se comportar como coadyuvantes en el proceso y aun consideran el problema como inherente solamente a la parte femenina. Se concluye que es imprescindible el abordaje de la cultura en las acciones de Educación en Salud para la promoción de la salud sexual y procreadora de la pareja. Se puede creer que, basados en estrategias de Educación en Salud culturalmente encaminadas, podrán ser alcanzados resultados de impacto positivo en la asimilación del riesgo y rotura de la cadena de transmisión de ESTs.

Palabras clave: Enfermedades de Transmisión Sexual. Salud de la Mujer. Enfermería.

${ }^{\dagger}$ Enfermeira. Mestre em Promoção da Saúde pelo Programa de Pós-graduação em Enfermagem, Universidade Federal do Ceará (UFC). Bolsista de pesquisa da Fundação Cearense de Apoio ao desenvolvimento Científico e Tecnológico (FUNCAP). Brasil. E-mail: leilanebarbosa@yahoo.com.br, ${ }^{2}$ Orientadora da pesquisa. Professora Emérita. Docente Livre do Departamento de Enfermagem da Universidade Federal do Ceará (UFC). Brasil. E-mail: grasiela@ufc.br 


\section{INTRODUCÃO}

Apesar do empenho de órgãos comprometidos com a saúde reprodutiva e sexual, as doenças sexualmente transmissíveis (DSTs) ainda constituem importante agravo de saúde pública. Segundo a Organização Mundial de Saúde, cerca de 12 milhões de DSTs são diagnosticadas a cada ano no Brasil, isso levando em consideração o fato de que apenas aproximadamente 200 mil casos/ano são notificados, visto que muitos portadores de DST não procuram tratamento qualificado ${ }^{1}$. Por esta razão, os dados referentes à incidência de DST são escassos, exceto em relação à AIDS e sífilis.

Em relação ao HIV, uma das DSTs mais preocupantes, verifica-se que eventos de transmissão entre heterossexuais apresentam uma tendência crescente, observando-se o crescimento entre mulheres. Em relação à razão do número de casos entre homens e mulheres, observa-se o crescimento da incidência nestas ${ }^{2}$. Portanto, mulheres que mantêm relações do tipo heterossexual compreendem a população que atualmente apresenta o maior crescimento de contaminação pelo HIV. Dentro desta população, encontram-se também mulheres em união consensual ou casadas.

Em interface a esta realidade relativamente recente está a influência de elementos culturais sobre o enfrentamento da situação pelo casal. A ação humana é direcionada pela "herança social" carregada de idéias, crenças, hábitos e costumes que, internalizados, influenciam a interpretação de situações ${ }^{3}$. Trazendo este raciocínio para a realidade de contaminação por DST, percebemos, em pesquisa anterior, por exemplo, que, muitas vezes, um dos membros do casal tende a associar a contaminação por DST a relações extraconjugais do parceiro ou parceira, desconsiderando outras possibilidades, como 0 período de latência e outras possíveis formas de infecção, no caso de DST, de transmissão frequentemente e eventualmente sexual $\left.\right|^{4}$. Além disso, quando a traição do parceiro ou parceira é confirmada, produz-se a mágoa e posteriormente 0 desencontro. Em uma relação estável, quando um dos parceiros aparece com uma DST, o outro pressupõe que a pessoa infectada manteve relação sexual fora do "casamento", e isso afeta o relacionamento ${ }^{5}$. Os autores afirmam ainda que a abordagem cultural da contaminação por DST no âmbito de uma relação estável pode representar, além de suporte emocional à mulher e a seu companheiro, a quebra da cadeia de transmissão.

0 entendimento da situação de casais que enfrentam a realidade da contaminação por DST, sobretudo sob uma óptica cultural, poderá contribuir para o desenvolvimento de estratégias de cuidado satisfatórias, com a co-participação do profissional de saúde e do cliente, uma vez que, segundo as maiores dificuldades de comunicação em saúde, residem na distância cultural e social entre o cliente e a equipe de saúde. É importante ressaltar, também, que clientes que experienciam cuidados de enfermagem culturalmente incongruentes com seus valores e modos de vida desenvolvem conflitos e estresse ${ }^{6}$.
A investigação sobre os elementos culturais que permeiam o diagnóstico de DST em mulheres em união estável poderá favorecer o desvelamento de crenças e valores que estejam influenciando o cuidado na promoção da saúde sexual e contribuir para elaboração e implementação de estratégias de educação em saúde mais eficazes, uma vez que o cuidado educativo congruente com a cultura tem maior possibilidade de obter êxito ${ }^{8}$. Com respaldo no conhecimento dos elementos da subjetividade presentes na inter-relação DST, cultura e cuidado de Enfermagem, portanto, poderão ser delineadas ações educativas culturalmente direcionadas, no intuito de atender a uma das estratégias de promoção da saúde presente no relatório de Lalond, de 1970: a reorientação dos serviços de saúde. Assim, desenvolvemos este estudo, que teve como objetivo analisar as significações da contaminação por DST para a mulher em união estável.

\section{METODOLOGIA}

Trata-se de um estudo fundamentado na Teoria do Cuidado Transcultural $\left.\right|^{8}$. Foi desenvolvido no Centro de Desenvolvimento Familiar (CEDEFAM), situado no bairro Planalto do Pici, localizado nas proximidades do Campus do Pici da Universidade Federal do Ceará (UFC). A escolha do campo obedeceu aos critérios de Winkin ${ }^{9}$, que orienta que campos de pesquisa em estudos etnográficos devem ter os limites correspondentes aos de um lugar público ou semipúblico, ser confortável, não oferecer perigo aparente à pesquisadora, ser um lugar simples que pode se revelar complexo à análise, ser adequado para realização de uma observação sistematizada e oferecer subsídios para que a pesquisadora retorne quantas vezes for necessário. 0 CEDEFAM oferece à população local, constituída em sua maioria por pessoas de baixa renda, assistência à saúde por meio de atividades realizadas por profissionais e estudantes da área. Dentre estas atividades, o incentivo à pesquisa e desenvolvimento científico são pontos for tes da dinâmica do CEDEFAM. Considerando a natureza do problema deste estudo, centralizei a investigação no contexto da consulta ginecológica de Enfermagem, realizada de terça-feira a sexta-feira, pela manhã, no Setor de Ginecologia do CEDEFAM.

Para seleção das informantes, estabelecemos os seguintes critérios de inclusão, que julgamos corresponder aos propósitos deste estudo: estar realizando atendimento no local e período do estudo; ser portadora de uma DST transmitida essencialmente ou frequentemente pela relação sexual; estar estabelecendo uma relação estável (casada ou em união consensual); morar em um local de fácil acesso e que não apresente riscos à vida da pesquisadora; e aceitar voluntariamente participar do estudo. A pesquisa foi realizada com suporte no depoimento de sete informantes-chave, entre as quais prevaleceram aquelas diagnosticadas com HPV(5) em detrimento das diagnosticadas com Trichomonas vaginalis (2). Em relação às mulheres selecionadas, cabe salientar que, em estudos fundamentados na Enfermagem Transcultural, o 
importante não é o número de informantes, mas sim 0 significado dos depoimentos em relação ao objetivo do estudo ${ }^{6}$.

No desenvolvimento da etnografia, o período de permanência do pesquisador no campo pode variar desde algumas semanas até meses ou anos, sendo que, quanto maior o tempo de permanência, maior a qualidade das informações coletadas $^{10,11}$. Considerando minha integral e exclusiva disponibilidade e a complexidade do fenômeno a ser analisado, desenvolvi a pesquisa em campo em um período de nove meses, o qual se estendeu de novembro de 2006 a julho de 2007.0 período de permanência de nove meses em campo foi necessário para a apreensão de nuances culturais e aproximação efetiva entre pesquisadora e informantes, o que favoreceu a obtenção de informações confiáveis sobre os contextos sócias e familiares das participantes do estudo.

Para a coleta de dados, segui as orientações do modelo "estranho-amigo" e modelo de Observação - Participação Reflexão (OPR), ambos de Leininger ${ }^{6}$. 0 padrão estranho-amigo me auxiliou a adentrar o universo das informantes, de modo a identificar, por meio de alguns indicadores propostos pela teórica, o momento em que avancei da posição de pesquisadora estranha para a de investigadora amiga. Isso significou, sob a perspectiva da investigação, uma relação pesquisadorainformantes mais verdadeira, na qual sentimentos e dados confiáveis foram compartilhados. Assim, ao perceber, de acordo com os apontamentos de Leininger ${ }^{6}$, que as participantes estavam menos desconfiadas, observavam menos minhas palavras e ações, cooperavam comigo como amigas, compartilhavam segredos culturais e experiências particulares, forneciam indícios de que estavam confortáveis com a pesquisa e tencionavam mostrar "verdades" em relação aos valores, crenças e modos de vida para a pesquisa, defini o momento de realizar a entrevista e encerrar o acompanhamento domiciliar. A entrevista foi composta pelas seguintes perguntas norteadoras: "como você reagiu ao receber o diagnóstico de portadora de uma doença sexualmente transmissível?"e "como ficou sua vida conjugal depois que você descobriu que era portadora de uma doença sexualmente transmissivvel?". As entrevistas foram realizadas na residência de cada informante, no cômodo da casa e no horário em que elas referiram como mais reservados e com menor possibilidade de interferência. 0 modelo OPR nos auxiliou a adentrar no universo cultural de forme gradativa, por meio de quatro fases: observação primária e escuta, observação primária com participação limitada, par ticipação primária com observação contínua, e reflexão e reconfirmação dos achados com as informantes. Para registro dos dados, utilizamos o diário de campo, que é instrumento insubstituível e deve ser priorizado como fonte de dados em uma investigação etnográfica9, 10,12.

0 exame dos dados ocorreu concomitantemente à coleta. Para isso, obedecemos às quatro fases para análise qualitativa de indicativos, descritas por Leininger ${ }^{6}$ : coleta, descrição e registro dos dados de forma bruta, identificação dos achados, análise contextual e dos pares, e síntese e agrupamento das idéias em temas maiores.

A pesquisa obedeceu às instruções presentes na resolução n 196, de 10 de outubro de 1996, do Comitê Nacional de Pesquisa, referente a estudos a serem realizados com seres humanos. Foi garantido o anonimato das participantes, aqui identificadas por pseudônimos baseados em deusas mitológicas de culturas diversas, assim como o direito de desistir do estudo quando considerassem necessário. Convém salientar que, para a realização desta pesquisa, foi solicitada à unidade de saúde a autorização para a realização da investigação. Foi encaminhado o projeto ao comitê de ética da Universidade Federal do Ceará (UFC), e, após aprovação, foi iniciada a coleta de dados.

\section{RESULTADOS E DISCUSSÃO}

\section{0 impacto do diagnóstico: morte social e afetiva da mulher}

As mulheres, após ouvirem três simples letras de seu diagnóstico: DST, algumas vezes até se mostrando num primeiro momento indiferentes à notícia, mergulham em um universo antes desconhecido ou até mesmo inimaginável. 0 pensamento de que "isso nunca vai acontecer comigo" dá lugar a muitas indagações, como: "Por que eu?", "0 que eu fiz de errado?", "0 que ele fez de errado?", "Como vamos fazer agora?".

Na vivência de um consultório de ginecologia, é possível ter uma idéia do primeiro impacto que a notícia provoca. Isso representa, entretanto, apenas a ponta de um iceberg. 0 que acontece no íntimo das clientes diagnosticadas após saírem do consultório? Muitos sentimentos ficam retidos e, após profunda reflexão acerca do que e de como aconteceu, podem ser extravasados com (ou entre) os possíveis culpados.

Após observar diversas reações em consultório de ginecologia, no momento do diagnóstico de DST, procurei investigar o que havia por trás de olhares de surpresa, de choros e expressões de indiferença. As entrevistadas revelaram os seguintes sentimentos e pensamentos ao descobrirem-se portadoras de uma DST:

Fiquei muito assustada... A sensação que eu tive foi de receber um resultado de AIDS. Deve ser muito ruim (receber um diagnóstico de HIV), tu é doida, mulher! (expressão de angústia). (ARIADNE).

Pra mim eu ia morrer já no outro mês. Na hora, ela (Enfermeira) me falando, eu fiquei normal... Até porque eu sou assim: tenho problemas, mas não consigo demonstrar as coisas (sentimentos). Mas quando eu cheguei em casa desabei no choro(...). (ATENA).

Quando a Enfermeira disse que poderia ser coisa de até 10 anos atrás eu me apavorei logo. Pensei: meu Deus, será que eu passei isso pra ele? Seráque fui eu? Era só no que eu pensava! No dia antes do exame dele eu chorei, de tão nervosa, com medo de ele me deixar. (KALU). 
Pensei que não tinha mais jeito! Ai, mulher, eu caí... A gente pensa logo nos filhos, no marido... Pensa logo que vai morrer! Fiquei tão nervosa que comecei a chorar. (DEMÉTER).

Os primeiros sentimentos experimentados com 0 diagnóstico, conforme os depoimentos, deixam explíita a idéia da perda da vida. 0 processo de descobrir-se com uma doença estigmatizante repercute na vivência da mulher, de modo que ela experimenta um estado de desorganização de seu mundo interno e externo ${ }^{13}$.

A notícia do diagnóstico de DST soa como sentença de morte, inicialmente apenas física. A relação entre DST-AIDS e DST-câncer prevalece no subconsciente das informantes, que interpretam o diagnóstico estigmatizante de acordo com suas visões de mundo que, por sua vez, se baseiam nas maiores preocupações divulgadas e observadas no cotidiano atual em relação às DSTs: a AIDS que mata e o HPV que pode propiciar o câncer de colo de útero, que também pode matar. Assim como um evento psicológico pode acarretar danos físicos, um evento físico pode favorecer o desenvolvimento de prejuízos de ordem psicossocial ${ }^{14,15}$. A idéia de morte desenvolvida desde 0 diagnóstico permanece no pós-diagnóstico, constituindo a morte social, do relacionamento amoroso, de toda uma vida de confiança no companheiro, a morte da autoestima, dentre outras perdas significativas para a qualidade de vida da mulher e/ou do casal. As DSTs ocasionam perdas que culminam na morte afetiva e social mediante a vergonha que os contaminados expressam de serem vistos como sujos, promíscuos e indignos e, ainda, de serem rejeitados pelo parceiro ou parceira ${ }^{16}$.

0 impacto do diagnóstico na mulher é representado pelo choro, que pode acontecer ainda no consultório de ginecologia ou depois. Procurando conhecer mais profundamente essa reação de choro das mulheres, descobri que ele possui vários significados e pode resultar de vários sentimentos. De acordo com o Dicionário Aurélio Básico, o ato de chorar possui 15 significados, dentre eles o de: exprimir tristeza e dor, com gemidos, soluços, acompanhados ou não de lágrimas; sentir profundo desgosto pela perda, falta ou ausência de alguma coisa; e sentir remorsos ou arrependimento de: chorar os pecados. 0 choro, uma reação natural, presente desde os primeiros instantes de nossas vidas, explica, com lágrimas ou sem elas, a tristeza e a dor causadas pela perda da saúde em seu sentido mais amplo e 0 arrependimento pelas condutas que levaram à contaminação pela DST. Chorar os pecados, neste contexto, parece ter ligação direta com o sentimento de culpa que as mulheres contaminadas carregam por seus diagnósticos. 0 choro consiste em uma representação feminina para a angústia vivenciada ante ao diagnóstico de HPV ${ }^{16}$.

Nos casos nos quais não foi diagnosticado HPV, mas sim Trichomonas vaginalis, a reação das informantes no instante e após o diagnóstico foi diferente, apesar de a tricomoníase tratarse também de uma DST. Isso pode ser observado nestes depoimentos:
Fiquei preocupada, mas ela (enfermeira) disse que eu não ficasse preocupada... Eu também não tinha raladura, nem inflamação... (ADIT).

Reagi bem, normal. Tratei de me cuidar. Não fui me entregar à doença. (ÁRTEMIS).

0 fato de a contaminação por Trichomonas vaginalis não estar relacionada diretamente com doenças que possam levar à morte colabora para que as mulheres não procurem maiores informações sobre a tricomoníase e que não a considerem um agravo significativo para sua saúde. Esse raciocínio ignora, também, o fato de que algumas DSTs podem servir de porta de entrada para outras. Neste contexto, ressalta-se, ainda, a concomitância da tricomoníase com outras DSTs e seu curto período de incubação, que pode ser um indicativo de infecção recente ${ }^{14}$.

Olhando por este ângulo, o diagnóstico pode ser sugestivo, em casais unidos há muitos anos, de relação sexual extraconjugal recente de alguma parte. 0 desconhecimento acerca disso, entretanto, e a pouca importância de uma DST, que, além de não trazer grandes malefícios de imediato, pode ser tratada facilmente, fazem com que o diagnóstico de tricomoníase passe desapercebido muitas vezes no cotidiano dos casais. Preocupante em relação a isso é o fato de que a prevenção para evitar novas contaminações pelo Trichomonas vaginalis, ou mesmo por outras DSTs, pode não ser considerada importante pelo casal.

A vigilância na prevenção de DST, no entanto, deve abranger a mulher e seu companheiro, o qual, mesmo não apresentando sintomas, está diretamente envolvido com o problema. Em alguns casos, no entanto, o homem pode permanecer indiferente à situação, em uma posição de espectador, isso muito em razão do desconhecimento sobre o HPV e outras DSTs menos conhecidas; afinal, DST parece se restringir apenas ao conceito de AIDS. As doenças diagnosticadas mediante 0 exame ginecológico parecem ser consideradas apenas "doença de mulher".

(...) Ele não teve nenhuma reação porque ele não tem conhecimento (sobre a doença). Se ele soubesse, do jeito que ele não apresentou nada, ele ia talvez brigar comigo, ele ia logo pensar: "que negócio é esse?" Se fosse uma coisa mais conhecida, uma AIDS, por exemplo, ele ia ficar me perguntando... (ARIADNE).

Neste estudo, grande parte dos companheiros não apresentou sintomas sugestivos de DST. As reações esperadas diante do fato de só as mulheres apresentarem sintomas poderiam ocasionar uma situação complicada: "se ela tem uma DST e eu não tenho nada, ela me traiu". Esta representação, frequentemente envolvendo a raiva como manifestação afetivoemocional, é característica do homem, substituindo o choro feminino ${ }^{16}$. Alguns homens, inicialmente, expressaram 
preocupação com a saúde "da companheira"; entretanto, essa preocupação foi semelhante à que ocorre em qualquer outra doença não transmitida por via sexual. Por outro lado, a idéia de contaminação sexual faz com que muitos despertem para a importância de tratar a doença, talvez para não serem contaminados, para impedir o agravo da saúde da companheira ou para proteger o filho, no caso de grávidas contaminadas. Diante disso, os homens parecem expressar maior interesse, interrogam sobre o tratamento e contribuem aderindo ao uso de medicamentos indicados para o acompanhamento do casal, embora ainda não tenham incorporado a importância de comparecer ao posto de saúde. Isso pode ser confirmado pelos depoimentos a seguir:

Quando eu contei pra ele: "Olha, eu to com um vírus, uma DST...", a primeira coisa que ele fez foi baixar a cabeça.(...) Quando eu disse do resultado e disse que teria que repetir o exame, ele me disse: "e não vai tomar nada pra matar isso?" Ainda ontem ele me perguntou se eu já marquei o exame (retorno). (ATENA).

\section{Ele ficou muito preocupado. (DEMÉTER).}

Ele ficou preocupado, mas ele tomou os comprimidos... Ela (enfermeira) disse que ele não ficasse preocupado. (ADIT).

Quando eu cheguei em casa, à noite, cheguei pra ele e disse que eu tava com um vírus e que ele teria que fazer um exame para ele saber se tinha o vírus também. Ele não falou nada, só disse assim: que era bom a gente fazer logo pra tratar (...) A preocupação dele era se ia afetar o bebê. (KALU).

A aproximação prévia do casal com as DSTs é carregada de vários elementos culturais, que podem ser expressos de formas diversas. A mulher, principalmente por ser diretamente envolvida com os sintomas e consequências, busca maiores informações sobre aquelas doenças nos sistemas de cuidados genéricos, conforme mostram as falas a seguir:

Por que eu vi como foi o tratamento da minha vizinha aquil Foi pesado! Ela e o marido dela fizeram um tratamento muito sofrido... (ARIADNE).

O médico disse que era uma coisa simples, mas que eu tinha que tratar, porque se não daria câncer quando eu tivesse 50 anos. Lá no CEDEFAM a enfermeira explicou logo que não é a mesma coisa que HIV (HPV). (...) mas eu tenho que dizer uma coisa (risos), só o fato de ser vírus já assusta a pessoa. Quando eu falei pra minha irmã que eu tava com um vírus ela disse: "Ai! Então pega!". As pessoas pensam que todo vírus pega assim, fácil, de ônibus, assento, copo... (KALU).
A busca por informações sobre o diagnóstico de DST e, mais especificamente, do tipo de DST resulta na formação de uma visão de mundo baseada na experiência de vizinhas ou parentes. A idéia de passar por uma experiência que possui significação entre indivíduos de seu contexto social remete a um sentimento ruim, promove o choque ante o diagnóstico, faz com que a cliente tenha uma visão de seu prognóstico em relação à doença ou mesmo desenvolva sentimentos ambíguos.

Outro fato interessante envolvendo a influência da etnohistória na repercussão do diagnóstico e na visão que as mulheres têm sobre sua contaminação reside na interpretação de que as DSTs são doenças imundas, de pessoas que não possuem higiene, envolvidas com pessoas promíscuas, ou até mesmo causadas por germes que se desenvolvem em razão da falta de higiene da mulher. Os depoimentos seguintes mostram significativamente esse pensamento:

Ela me explicou tudo: que eu poderia ter pegado dele, que poderia regredir ou aumentar... Mas foi mesmo que nada pra mim (...) eu olhava pra essas mulheres daqui da rua que passam o dia sentadas nas calçadas, sujas, fedorentas, e que todo mundo sabe que o marido é cheio de mulher, e me pergunto: por que deu essa vírus em mim? Ela (vizinha) fez exame e deu: inflamação moderada. Já o meu deu esse problema! E eu me cuido tanto! Olha, eu só lavo minhas calcinhas com sabão de coco, não deixo a calcinha estendida no varal com o fundo pra fora pra não pegar mosquito, me lavo com Dermacid... Isso é que eu queria saber! (ATENA).

Ela disse que ia passar dois comprimidos para matar o germezinho (...) Ela disse que eu tomasse e pronto. Matava o germe e pronto (...) Esse germezinho que a gente, mulher, tem, né?(ADIT).

A mulher "não limpa" dentro do estereótipo da cultura de gênero passa a ser a principal fonte das doenças. Essa idéia foi expressa principalmente na indignação de Atena em ver que suas vizinhas não possuem DST, ao contrário dela que, mesmo tendo extremos cuidados de higiene, foi contaminada. Isso pressupõe a crença de que, ao se relacionar com mulheres limpas, não há risco de contrair DST. A relação das DSTs com mulheres sujas advém de muitos anos, desde os primórdios da saúde pública brasileira, quando a idéia disseminada nas campanhas de "higiene e saúde" ficou retida no subconsciente social, induzindo algumas pessoas a confundirem os conceitos sujeira, limpeza, saúde e pureza dentro do universo da sexualidade ${ }^{17}$.

Concomitante ao sentimento de nojo, mal-estar e indignação diante da realidade de portar uma DST, o casal ainda experimenta uma série de conflitos relacionados ao fenômeno da contaminação. Além de afetar o âmbito biológico, 
as DSTs, principalmente quando presentes no cotidiano familiar, ocasionam danos expressivos na vida social e afetiva. A baixa autoestima da mulher contaminada, aliada aos sentimentos de mágoa e desconfiança a respeito de uma possível traição do companheiro, pode culminar em um distanciamento entre 0 casal, que, por sua vez, vai afetar toda a dinâmica familiar. Valores e tensões permeiam os relacionamentos conjugais, impondo normas e significados referentes ao comportamento do homem e da mulher nas diferentes situações do cotidiano. Assim, diante do conflito originado pela descoberta de uma DST, desenvolve-se um ambiente propício para o julgamento de quem errou, quem ultrapassou os limites do desejo no relacionamento estável.

\section{Relacionamento do casal e comportamento sexual após o diagnóstico}

Ao perceber-se contaminada por uma doença que a pode levar a desenvolver câncer ginecológico, a mulher reflete sobre suas condutas e aos comportamentos de seu companheiro. Procura saber de quem é a culpa. E quando ele foi "o único", a situação torna-se ainda mais complicada, uma vez que só resta uma resposta, de acordo com a crença dela: ele manteve relacionamento extraconjugal. Ao se descobrir portadora de uma DST, a pessoa pode desenvolver autorreflexão a respeito da vida amorosa, das situações vividas com cada parceiro e da origem da contaminação.

A possibilidade do período de latência parece ser algo ainda desconhecido ou pouco presente no universo cultural investigado, e, portanto, relações sexuais anteriores à união do casal parecem ser desconsideradas pela mulher como fonte de contaminação do companheiro pelo HPV, mesmo em face das informações e orientações fornecidas pelo sistema de cuidados profissionais. Quando não apresenta sinais nem sintomas, o homem permanece insensível ao problema; mas a mulher, diretamente afetada com as consequências, tende a apresentar mudanças em seus sentimentos e comportamentos em relação ao companheiro, conforme confirmado nos depoimento a seguir:

Do dia do resultado do exame do CEDEFAM até o dia da consulta (na unidade de referência para DST) a gente não teve relação (...) (KALU).

Mudei muito, fiquei muito diferente com ele (...) Ele não mudou nada. Ele não pergunta nada sobre a doença porque não é esclarecido, não sabe nemo que é... Você saber que tem uma doença como essa, séria, e que não foi seu corpo que produziu... (expressão de rancor e mágoa). Por que quando você não sabe de onde vem a doença, tudo bem... Mas quando você sabe que a culpa édele!Por que o único homem que eu tive foi ele... Ejá faz dez anos que a gente tá junto... Tem até um filho, mulher! Eu fiquei perguntando se ele não teve com mulher por aí, ele disse que não... (tom de dúvida) (ARIADNE).
0 comportamento sexual antes da contaminação é determinado pela falta de cuidado do casal em relação à prevenção de DST, mais especificamente pela não-adesão ao uso do preservativo por parte do homem e pela ineficiência do poder de negociação e submissão da mulher. A importância que os homens atribuem à vivência do momento da relação sexual os leva a não avaliar as consequências do sexo dito não seguro, e a confiança que as mulheres têm em seus parceiros as fazem submissas do desejo deles ${ }^{16}$.

Após a contaminação, porém, a mulher desenvolve pensamento crítico sobre sua condição de saúde e acerca de seu "amor inconsequente". A gravidade que doenças como 0 câncer e a AIDS adquiriram no imaginário popular e suas correlações com o sistema de cuidados populares proporcionaram um cenário favorável para 0 autocuidado. Em um comportamento de autoproteção, as mulheres seguem rigorosamente as condutas orientadas pelos profissionais de saúde e evitam relações sexuais, temendo outras contaminações ou o agravo de sua doença, conforme confessam estas entrevistadas:

Depois da consulta (na unidade de referência para DST), que a gente descobriu que os dois têm o virus, e que o doutor disse que a gente podia ter, a gente tem relação usando camisinha. (KALU).

Só tive relação (sexual) com ele depois que a Dra me deu alta (...) Nem com camisinha nem sem camisinha (...)(ARIADNE).

A minha vida com ele mudou. Mudou mais da minha parte. Como eu te falei antes, eu sempre fico com medo quando o pênis dele penetra porque eu acho que a ferida no útero vai se abrindo. Ele não sabe disso... Quer dizer, eu acho que ele sabe... Eu espero que ele saiba! (risos) Mas mudou muito porque sempre eu fico dizendo: "Não, assim não, não coloca toda" Aí quando ele vem eu fico perguntando também: "Já lavou as mãos? Tomou banho?" Sei que isso quebra o clima. (ATENA).

Só depois do tratamento ficou tudo normal. A médica passou uma pomada vaginal e disse que eu tava de alta... Eu entendi que eu tava de alta pra ter relações... (...) Continuei tendo relações com camisinha. 0 comportamento dele não mudou... Quando fiz a CAF era pra ela (médica) ter me dado alta com um mês, aí eu fiquei esse tempo sem ter relações... Acho que a gente não devia ter relações porque fica batendo (no colo uterino), né? Meu medo é no futuro. A gente peleja pra esquecer, mas de vez em quando lembra... (DEMÉTER) 
É interessante observar que, após o diagnóstico, as entrevistadas parecem ter (re)descoberto seus corpos. Uma anatomia antes desconhecida passa a adquirir familiaridade na linguagem das mulheres, e a preocupação com os órgãos diretamente afetados pela DST, no caso dos últimos depoimentos, pelo HPV, é verbalizada e relacionada a crenças recentes constituídas na relação entre as informações profissionais e genéricas.

Ao receber o diagnóstico de portadora do HPV, a mulher procura informar-se sobre essa doença estranha, desconhecida. Ao encontrar a relação entre HPV e colo uterino, sobretudo tendo o estigma da palavra câncer permeando esta realidade, elas parecem desenvolver pensamentos sobre o que está acontecendo em seus corpos, a respeito da lesão (compreendida como ferida) que o vírus causa, e acerca de como podem se proteger de forma a evitar o mínimo de transtorno. Assim, compreendendo que durante a relação sexual o pênis pode atingir o colo uterino, elas evitam a penetração ou, pelo menos, a penetração profunda, pois acreditam que "o contato com o colo do útero pode fazer com que a ferida aumente". Em estudo anterior, verifiquei que mulheres portadoras do HPV, após receberem o diagnóstico e serem devidamente esclarecidas sobre a doença e as condutas durante e após o tratamento, apresentaram uma atitude de autocuidado e cuidado com o parceiro ${ }^{4}$.

As prevenções e cuidados oriundos de crenças e outros elementos culturais, apesar de trazerem prejuízos pelas punições exageradas em razão da doença, estimularam o autocuidado da mulher, despertando-a para um fato: a importância do autoconhecimento e da autoestima para o autocuidado. Infelizmente, esses valores só são incorporados após um evento negativo significativo, vivenciado pela própria mulher no processo saúde-doença.

Talvez por conta de a mulher não ter, muitas vezes, dentro da sociedade e dos sistemas de saúde, oportunidade para desenvolver reflexão e pensamento crítico a respeito de seus direitos como cidadã e de sua autonomia no contexto da promoção de sua própria saúde, tenha se submetido a situações de risco por conta do amor e confiança em seu companheiro, ou mesmo pela falta de conscientização sobre a importância do amor próprio e da emancipação como elementos de promoção da saúde.

\section{A proteção à saúde em interface à dependência emocional da mulher}

Uma das informantes, que possui dependência de seu parceiro no plano econômico, sentimental e sexual, mesmo após o diagnóstico, continua se expondo à contaminação pelo vírus HPV durante seu tratamento. Esta informante foi destacada porque, embora diferente das demais participantes do estudo (pois, mesmo após a contaminação, não apresentou comportamento de autocuidado), pode representar uma parcela da população feminina que necessita de um estímulo maior que o diagnóstico para a autorreflexão a respeito de sua autonomia e capacidade de emancipação diante dos problemas incorporados no contexto saúde-doença, principalmente no âmbito sexual e reprodutivo. 0 contexto sociocultural e a condição psicossocial da informante fazem-na crer que 0 diagnóstico de DST soaria para o parceiro como uma prova de que ela estabeleceu relacionamento extraconjugal, o que, por sua vez, poderia acarretar a separação do casal. Isso é algo inimaginável para a informante, que atribui ao relacionamento e ao julgamento do parceiro um valor maior do que ao da proteção da própria saúde. 0 depoimento a seguir expressa parte do sentimento da referida informante:

Mas ainda fiquei sem querer contar a ele... Porque eu tenho medo de ele saber (do diagnóstico de DST) e ir atrás de saber se eu fiquei com outro homem. (...). Eu não quero que ele saiba que eu fiquei com outro homem porque ele vai achar que esse filho que vai nascer não é dele. (...) Minha vida conjugal continuou do mesmo jeito, porque ele vive vindo aqui, a gente tem relação... Mas como eu disse: a gente tem relação sem camisinha porque ele não gosta de usar e eu não posso contar do HPV. (PANDORA).

As mulheres, antes ou após a contaminação, necessitam de oportunidade de reflexão sobre seu estado de saúde-doença, principalmente no que tange ao âmbito da sexualidade, em que a submissão e a ineficiência do poder de negociação pela busca da saúde do casal ainda permanecem, mesmo depois das tão ressaltadas conquistas femininas na sociedade. As questões de gênero, representadas pela submissão feminina no relacionamento sexual, parecem constituir entraves ainda maiores do que a falta de informação, uma vez que englobam também elementos culturais fortemente enraizados na sociedade.

Apesar de não sermos capazes de conscientizar ninguém, podemos fornecer meios para que a pessoa desenvolva a própria conscientização. E esse meio é promovendo a autorreflexão. Por intermédio da reflexão, o ser humano é capaz de assumir um compromisso de mudança para alcançar saúde e qualidade de vida por meio da autonomia. Nesse contexto, o autor assegura que apenas o ser humano é capaz de se erguer e enfrentar seus problemas, e que para isso deverá estar em contato com a realidade e compreender-se como parte dela. Assim ele não será apenas um produto da cultura e da sociedade, mas um sujeito de transformação de sua visão de mundo e de seu modo de vida.

As pessoas possuem direitos em relação ao cuidado da própria saúde. Nesse sentido, resta ao profissional compreender que deve promover o que os autores denominam de alfabetização para a saúde, a fim de que a cliente realize uma opção informada e aceite a responsabilidade de suas escolhas para sua saúde. 


\section{CONSIDERAÇÕES FINAIS}

Por meio deste estudo, desvela-se o paradoxo entre 0 investimento na prevenção de DST e crescente número de mulheres contaminadas. 0 evento da contaminação por DST envolve ações de cuidado que passam por questões de gênero e cultura, as quais, por vezes, se entrelaçam. Isso pode ser percebido na ineficiência do poder de negociação da mulher quanto ao uso da camisinha, na submissão feminina que faz com que a mulher negligencie o cuidado na prevenção de DST em decorrência da supervalorização do desejo do parceiro e na idéia de que DSTs são problemas apenas de mulher.

Como agravante, é possível identificar que o homem se comporta como coadjuvante no problema, isso em parte por conta da ausência de sinais e sintomas e da importância que eles dão ao prazer do momento da relação sexual, negligenciando condutas de autocuidado. Esses conceitos parecem estar enraizados culturalmente nas relações entre homens e mulheres, que assumem papéis passivo e ativo, respectivamente, no processo de cuidado da saúde sexual e reprodutiva do casal. A consciência a respeito da vulnerabilidade do corpo feminino às DSTs possui origens culturais de gênero enraizadas que enfatizam a representação das figuras masculina e feminina, sobrepondo suas singularidades.

0 advento do diagnóstico desperta, além de mágoa e de autopunição, sentimentos de autocuidado e proteção da saúde. Depois de descobrir-se portadora de uma DST, a mulher revisa comportamentos de submissão e passa a expressar indícios de autonomia sobre seu corpo. Esse impacto positivo, contudo, varia de acordo com o tipo de DST diagnosticada. DSTS diretamente envolvidas com a morte, o HIV e o HPV (no imaginário popular) repercutem de modo mais decisivo, pois estas DSTs podem culminar na AIDS e no câncer de colo de útero. Já no caso de contaminação por Trichomonas vaginalis, a preocupação é momentânea. Apesar das orientações dos serviços de saúde, as mulheres não atribuem significativo valor à tricomoníase, desconsiderando o fato de ela servir de porta de entrada para outros tipos de DST.

Tomando essas evidências, revelam-se pontos positivos e negativos que precisam ser trabalhados dentro da complexidade da contaminação por DST em casais em união estável. A realidade do desenvolvimento de um comportamento de cuidado após o evento negativo do diagnóstico merece visão mais apurada de profissionais de saúde, pois representa, de certa forma, uma expressão cultural de cuidado. 0 antes e o depois da contaminação, na dinâmica do casal, revela que a mulher "acorda" para a importância de cuidar da saúde sexual e reprodutiva depois de um evento negativo vivenciado.

Com a promoção da autorreflexão da mulher por meio da "sentença" de estar contaminada por uma DST, lançam-se bases para o desenvolvimento da conscientização não apenas diante de eventos negativos, mas, sobretudo, na prevenção dessas doenças. Ressalta-se a alternativa de realizar uma abordagem de empowerment (empoderamento) relacionado a esse momento vivenciado pelo casal e, mais especificamente, pela mulher, para conscientização sobre o risco de novas contaminações e quebra da cadeia de transmissão.

É necessário possibilitar a reflexão das mulheres sobre a autonomia que possuem (devem possuir) sobre seus corpos, promover a conscientização masculina sobre a responsabilidade do casal (e não só da mulher) a respeito da saúde sexual do casal e elaborar estratégias educativas para que a questão do risco e da contaminação por DST seja tratada com o emprego de uma abordagem positiva.

\section{REFERÊNCIAS}

1.Dados e pesquisas em DST e AIDS. [citado 20 ago 2006]. Disponível em http://www.AIDS.gov.br/final/dados/dst.htm.

2. Boletim Epidemiológico AIDS. Brasília (DF): Ministério da Saúde; 2006

3.Costa MH, Carbone MH. Saúde da família: uma abordagem interdisciplinar. Rio de Janeiro (RJ): Rubio; 2004.

4.Sousa LB. Ser mulher portadora do HPV: uma abordagem cultural. [Trabalho de Conclusão de Curso] Fortaleza (CE): Departamento de Enfermagem/UFC; 2005.

5.Passos MRL, Passos MDL, Passos ZPS. Aspectos psicossociais das DST. In: Passos MRL, organizador. Deessetologia- DST 5. Rio de Janeiro (RJ): Cultura Médica; 2005. p. 867-73.

6.Leininger MM. Culture care diversity and universality: a theoria of nursing. New York(USA): National League for Nursing Press; 1991.

7.Ministério da Saúde (BR). Promoção da Saúde. Declaração de AlmaAta, Declaração de Adelaide, Declaração de Santafé de Bogotá, Rede dos mega-países, Carta de Ottawa, Declaração de Sundsvall, Declaração de Jacarta, Declaração do México. Brasília (DF): 2001.

8.Leininger MM. Transcultural nursing: concepts, theories, research e practice. [s.l.]: Mc Graw-Hill; 2002.

9.Winkin Y. A nova comunicação: da teoria ao trabalho de campo. Campinas (SP): Papirus; 1998.

10. André M. Etnografia da prática escolar. Campinas (SP): Papirus; 1995.

11.Ross DD, Kyle DW. Qualitative inquiry: a review and analysis. Trabalho apresentado no Encontro Annual da AERA. New York(USA); 1982.

12.Sousa LB, Barroso MGT. Pesquisa etnográfica: evolução e contribuição para a enfermagem. Esc Anna Nery Rev Enferm 2008 mar; 12 (1): 150-55.

13.Silva ARB, Mereghi MAB. Compreendendo o estar com câncer ginecológico avançado: uma abordagem heideggeriana. Rev Esc Enferm USP 2006; 40 (2): 253-60.

14.Duarte G. DST durante a gravidez e o puerpério. In: Passos MRL, organizador. Deessetologia: DST 5. Rio de Janeiro (RJ): Cultura Médica; 2005. p. 685-705.

15.Morin E. Saberes globais e saberes locais: o olhar transdisciplinar. Rio de Janeiro (RJ): Garamond; 2000.

16.Alves MDS. Papilomavírus e mal-estar: representações sociais de homens e mulheres. Fortaleza (CE): Pós-Graduação /DENF /UFC / Fundação Cearense de Pesquisa e Cultura; 2004.

17.Villela WV. Saúde sexual e reprodutiva como direitos humanos. In: Passos MRL, organizador. Deessetologia DST 5. Rio de Janeiro (RJ): Cultura Médica; 2005. p. 737-42. 